\title{
Effects of Essential Fatty Acids during In Vitro Maturation of Porcine Oocytes: Hormone Synthesis and Embryonic Developmental Potential
}

\author{
Kang-Sig Kim ${ }^{1}$ and Hum-Dai Park ${ }^{2, *}$ \\ ${ }^{1}$ Ellemedi Obstetrics and Gynecology, Changwon 51191, Korea \\ ${ }^{2}$ Department of Biotechnology, Daegu University, Gyeongsan 38453, Korea
}

Received April 15, 2019

Revised May 22, 2019

Accepted May 29, 2019

\author{
*Correspondence \\ Hum-Dai Park \\ Department of Biotechnology, Daegu University, \\ 201, Daegudae-ro, Jillyang-eup, Gyeongsan \\ 38453, Korea \\ Tel: +82-53-850-6554 \\ Fax: +82-53-850-6550 \\ E-mail: humdai@daegu.ac.kr \\ ORCID \\ https://orcid.org/0000-0002-3721-9167
}

\begin{abstract}
Omega-3 $\alpha$-linolenic acid and omega- 6 linoleic acid are essential fatty acids for health maintenance of human and animals because they are not synthesized in vivo. The purpose of this study was to evaluate the effect of $\alpha$-linolenic acid and linoleic acid supplementation on in vitro maturation and developmental potential of porcine oocytes. Various concentrations of $\alpha$-linolenic acid and linoleic acid were added into in vitro maturation medium, and we evaluated the degree of cumulus expansion, oocyte nuclear-maturation rate, blastocyst rate, blastocyst quality, and levels of prostaglandin $\mathrm{E}_{2}, 17 \beta$-estradiol, and progesterone in the spent medium. High doses $(100 \mu \mathrm{M})$ of $\alpha$-linolenic acid and linoleic acid supplementation significantly inhibited cumulus expansion and oocyte nuclear maturation, and prostaglandin $\mathrm{E}_{2}$ synthesis also significantly decreased compared with other groups $(p<0.05)$. Supplementation of $50 \mu \mathrm{M} \alpha$-linolenic acid and $10 \mu \mathrm{M}$ linoleic acid showed higher quality blastocysts in terms of high cell numbers and low apoptosis when compared with other groups $(p<0.05)$, and synthesis ratio of $17 \beta$-estradiol / progesterone also significantly increased compared with control group (3.59 \pm 0.22 vs. $2.97 \pm$ $0.22,3.4 \pm 0.28$ vs. $2.81 \pm 0.19$, respectively; $p<0.05)$. Our results indicated that supplementation with appropriate levels of $\alpha$-linolenic acid and linoleic acid beneficially affects the change of hormone synthesis (in particular, an appropriate increase in the $17 \beta$-estradiol / progesterone synthesis ratio) for controlling oocyte maturation, leading to improved embryo quality. However, high doses of $\alpha$-linolenic acid and linoleic acid treatment results in detrimental effects.
\end{abstract}

Keywords: $\alpha$-linolenic acid, linoleic acid, porcine oocytes, prostaglandin, $17 \beta$-estradiol / progesterone

\section{INTRODUCTION}

Oocytes maturation is critical factor in determining its developmental potential and embryo quality produced after fertilization, and appropriate steroid and eicosanoid secretion are essential for optimal maturation (Sirard et al., 2006). During folliculogenesis until the LH surge, the concentration of $17 \beta$-estradiol (E2) is high in the follicular fluid. Subsequently, the LH surge stimulates the transformation of theca and granulosa cells into luteal cells, which begin to produce progesterone (P4) instead of E2 (Walsh et al., 2012). Therefore, sex steroids (such 
as E2 and P4) present in follicular fluid might be key factors that determine the fate of the oocytes (Hyttel et al., 1986). It has been well demonstrated that $\mathrm{E} 2$ is essential during follicular growth (Lubahn et al., 1993). However, high E2 concentrations during final maturation induce oocyte nuclear aberrations and inhibit meiotic progression in bovine species (Beker-van et al., 2004). It has been also demonstrated that $\mathrm{P} 4$ is an important factor in oocyte development and ovulation (Lydon et al., 1995). Additionally, supplementation of $\mathrm{P} 4$ into maturation medium stimulates meiotic resumption in bovine (Siqueira et al., 2012) and porcine (Yamashita $Y$ et al., 2003) oocytes. However, Wathes et al. (2007) also reported that increased P4 in IVM medium has a negative effect on oocyte-developmental potential, resulting in the production of poorquality embryos. Modina et al. (2014) reported that the E2/P4-synthesis ratio in follicular fluid has been used as a surrogate marker for healthy and atretic follicles. These results suggested that $\mathrm{E} 2$ and $\mathrm{P} 4$ seem to act in opposition to nuclear maturation, and furthermore, balance in optimal hormone levels in follicular fluid during final maturation is crucial for oocyte development and the production of good-quality embryos. One of the eicosanoids, prostaglandins (PGs) playing important roles in reproductive functions, such as estrous, ovulation, embryo survival, and parturition (Abayasekara et al., 2009), and serving as critical mediators during oocyte maturation (Neal et al., 1975). Prostaglandin $\mathrm{E}_{2}\left(\mathrm{PGE}_{2}\right)$ is the dominant $\mathrm{PG}$ in the preovulatory follicles (Segi et al., 2003), and many studies have shown that $\mathrm{PGE}_{2}$ plays important roles in cumuluscell expansion and oocyte maturation in rodents (Takahashi et al., 2006) and cattle (Nuttinck et al., 2011). Hizaki et al. (1999) reported abortive expansion of the cumulus and impaired fertility in mice lacking the PGE-receptor. Additionally, $\mathrm{PGE}_{2}$ is thought to act as luteotrophic factor in the early luteal phase (Ghaffarilaleh et al., 2014), and are known to affect steroid hormone secretion indirectly (Wathes et al., 2007).

It has been shown that changes in the type and concentrations of polyunsaturated fatty acids (PUFAs) in diet can alter ovarian environment through such as changes in steroid and eicosanoid secretion, and such alternation also affects the oocyte maturation and embryo developmental potential and furthermore the pregnancy rate (Mattos et al., 2000). Although PUFAs have important effects on reproductive function because they may be involved in reproductive process as precursor of steroid hormone (via cholesterol) and of PGs (via arachidonic acid), very few studies have been provided detailed descriptions of their nature and mechanism. Importantly, different types of PUFA supplementation have differential effects on reproductive function (Gulliver et al., 2012). PUFAs have more than one double bond present within the molecule, and omega- 3 and omega- 6 series are classified according to the location of the first double bond (Wathes et al., 2007). The three types of omega-3 fatty acids involved in human physiology are a-linolenic acid (ALA: C18:3), eicosapentaenoic acid (EPA: C20:5), and docosahexaenoic acid (DHA: C22:6). The four types of omega-6 fatty acids involved in human physiology are linoleic acid (LA: C18:2), gamma-linolenic acid (GLA: C18:3), dihomogamma-linolenic acid (DGLA: C20:3), and arachidonic acid (AA: C20:4). In mammals, ALA can be transformed to EPA and DHA, LA can be transformed to DGLA and AA. However, animals cannot synthesize ALA and LA de novo, as they lack the appropriate fatty acid desaturase enzymes. Therefore, both need to be provided in the diet, given their requirement for numerous processes, including growth, reproduction, vision, and brain development (Wathes et al., 2007). For this reason, they are called essential fatty acids (EFAs) (Wiktorowska-Owczarek et al., 2015).

Most omega-3 PUFAs are derived in ALA, localizes in the plasma and follicular fluid (Wathes et al., 2007) and positively affects oocyte development (Childs et al., 2008). Veshkini et al. (2015) found that the amount of ALA increases as ovarian follicles enlarge. Additionally, ALA is involved in the regulation of meiotic arrest at the germinal vesicle (GV) stage development (Wathes et al., 2007). Bovine oocyte supplementation with ALA during IVM results in an increased maturation rate, a higher blastocyst yield, and production of better-quality blastocyst embryos (Marei et al., 2009). Furthermore, during IVM, COCs treated with ALA show significant increases in $\mathrm{PGE}_{2}$ concentration in the spent medium. Similarly, Ghaffarilaleh et al. (2014) reported that ALA affects prepubertal sheep-embryo quality associated with alterations in released reproductive hormones. Another EFA, omega-6 LA is abundant in follicular fluid and detrimentally affects oocyte development. LA-supplemented feed negatively affects fertility in cattle as compared with ALA supplementation (Santos et al., 2008), and Marei et al. (2010) reported that treat- 
ment of COCs with LA during IVM significantly inhibits cumulus-cell expansion and retards oocyte development at the metaphase II (MII) stage in a dose-dependent manner. LA also significantly lowers the percentage yield of cleaved embryos and blastocyst embryos, and increases $\mathrm{PGE}_{2}$ concentration in the spent medium. LA-induced alterations in mitochondrial distribution and activity, as well as increases in levels of reactive oxygen species, partially mediate the inhibitory effect on oocyte maturation (Marei et al., 2012). By contrast, positive reports associated with addition of appropriate concentrations of LA to a defined maturation medium showed no alterations in the nuclear status of bovine oocytes matured in vitro, but improved their quality by increasing the neutral lipid content stored in lipid droplets (Carro et al., 2014). Moreover, fatty acid-content analysis of bovine follicular fluid collected from different-sized follicles showed significantly lower LA concentration in large follicles as compared with small follicles (Homa et al., 1992). These reports revealed that the physiological decrease in LA concentration in follicular fluid might be important to oocyte maturation, and that LA might play a role in controlling oocyte maturation. Consequently, the types and quantity of PUFAs added during IVM might play an important mediatory role in oocyte maturation by inducing changes in PGs, E2, and P4 synthesis, which could result in the production of high-quality blastocyst embryos.

In order to investigate the effect of EFA on oocyte maturation, we assessed whether supplementation with the ALA and LA to porcine oocyte IVM medium affected cumulus expansion and oocyte nuclear-maturation rate, developmental rate to the blastocyst stage, and blastocyst quality, as well as concentrations of $\mathrm{PGE}_{2}$ and sex steroids (E2 and P4) in the spent medium.

\section{MATERIALS AND METHODS}

\section{Chemicals and reagents}

All chemicals used in this study were purchased from Sigma-Aldrich (St. Louis, MO, USA). Medium for oocyte washing, maturation, and culture was pre-incubated at $38.5^{\circ} \mathrm{C}$ and $5 \% \mathrm{CO}_{2}$ in an air incubator for at least $4 \mathrm{~h} \mathrm{be-}$ fore use.

\section{Oocyte collection and in vitro maturation}

Porcine ovaries were collected from a local abattoir and transported to the laboratory in a thermos container in $0.9 \%$ saline supplemented with $75 \mu \mathrm{g} / \mathrm{mL}$ potassium penicillin $\mathrm{G}$ at between $\sim 25^{\circ} \mathrm{C}$ and $30^{\circ} \mathrm{C}$ within $2 \mathrm{~h}$ after killing. They were washed in fresh $0.9 \%$ saline supplemented with $75 \mu \mathrm{g} / \mathrm{mL}$ potassium penicillin $\mathrm{G}$ immediately after arrival. COCs were aspirated through an 18-gauge needle into a disposable $10-\mathrm{mL}$ syringe from follicles $3 \mathrm{~mm}$ to 6 $\mathrm{mm}$ in diameter (Homa et al., 1994). After washing three times with HEPES-buffered Tyrode's medium (TL-HEPES), $\sim 50$ COCs were matured in $500 \mu \mathrm{L}$ IVM medium in a 4-well multi-dish (Nunc, Roskilde, Denmark) at $38.5^{\circ} \mathrm{C}$ and $5 \% \mathrm{CO}_{2}$ in an air incubator. The basic medium used for oocyte maturation was North Carolina State University medium 23 (NCSU-23) supplemented with $6 \mathrm{mg} / \mathrm{mL}$ fatty acid-free bovine serum albumin (BSA; Sigma-Aldrich), $0.57 \mathrm{mM}$ cysteine, $10 \mathrm{ng} / \mathrm{mL} \beta$-mercaptoethanol, $10 \mathrm{ng} /$ $\mathrm{mL}$ epidermal growth factor, $10 \mathrm{IU} / \mathrm{mL}$ pregnant mare's serum gonadotropin (PMSG), and $10 \mathrm{IU} / \mathrm{mL}$ human chorionic gonadotropin (hCG) (Petters et al., 1993). After 22 $\mathrm{h}$ of culture, oocytes were washed three times and then further cultured in maturation medium in the absence of hormone supplements (PMSG or hCG) for $22 \mathrm{~h}$. After completion of IVM, oocytes were subjected to in vitro fertilization.

\section{In vitro fertilization and culture}

In vitro fertilization of porcine oocytes was performed as described previously (Abeydeera et al., 1997). Fresh semen was kindly supplied once a week by the AI Company (Darby Pig AI Center, Anseong, Korea) and stored at $17^{\circ} \mathrm{C}$ for 5 days. Semen was washed three times by centrifugation with Dulbecco's phosphate-buffered saline (DPBS; Gibco BRL, Grand Island, NY, USA) supplemented with 1 $\mathrm{mg} / \mathrm{mL}$ BSA (Fraction V; Sigma-Aldrich), $100 \mathrm{mg} / \mathrm{mL}$ penicillin $\mathrm{G}$, and $75 \mathrm{mg} / \mathrm{mL}$ streptomycin sulfate. After washing, spermatozoa were resuspended in modified Trisbuffered medium (mTBM) at pH 7.8. Oocytes were washed three times in mTBM with $2.5 \mathrm{mM}$ caffeine sodium benzoate and $1 \mathrm{mg} / \mathrm{mL}$ BSA (fatty acid free) and placed into $48 \mu \mathrm{L}$ mTBM under paraffin oil, followed by addition of 2 $\mu \mathrm{L}$ of diluted spermatozoa to the $48-\mu \mathrm{L}$ drop of the medium containing between $\sim 15$ and $\sim 20$ oocytes at a final concentration of $1.5 \times 10^{5} \mathrm{sperm} / \mathrm{mL}$. The oocytes were co-incubated with spermatozoa for $6 \mathrm{~h}$ at $38.5^{\circ} \mathrm{C}$ and $5 \%$ $\mathrm{CO}_{2}$ in an air incubator. After fertilization, the embryos were cultured in $50-\mu \mathrm{L}$ drops of porcine zygote medium-3 
(PZM-3) supplemented with $3 \mathrm{mg} / \mathrm{mL}$ BSA at $38.5^{\circ} \mathrm{C}$ and $5 \% \mathrm{CO}_{2}$ in an air incubator. After $48 \mathrm{~h}$ of culture, 25 to 30 cleaved embryos were further cultured in $50 \mu \mathrm{L}$ PZM3 medium supplemented with $3 \mathrm{mg} / \mathrm{mL}$ BSA for 4 days. Blastocyst embryos were observed after 6 days of culture.

\section{Oocyte-maturation assessment: cumulus-cell expansion and nuclear stage}

After $44 \mathrm{~h}$ of maturation, the degree of cumulus expansion was assessed subjectively using a stereomicroscope and qualified as not expanded, partially expanded (the outer layer of cells was loosened), or fully expanded (all cumulus cells were loosened). Additionally, to assess the stage of nuclear maturation at the end of the maturation time, oocytes were stained with aceto-orcein as described previously (Marei et al., 2009). Representative samples of oocytes were denuded by gentle pipetting in NCSU-23 medium containing $0.1 \%$ hyaluronidase, washed in DPBS supplemented with $0.1 \%$ BSA, and mounted on microscope slides. The samples were fixed in acetic acid:ethanol (1:3, v/v) after 3 days and stained with acetic orcein $0.1 \%(\mathrm{v} / \mathrm{v})$ for $5 \mathrm{~min}$. The samples were destained in glycerol:acetic acid:water (1:1:3, v/v/v), and the nuclear stage was evaluated under a microscope at $200 \times$ and 400 $\times$ magnification (Leica, Solms, Germany).

\section{$\mathrm{PGE}_{2}$ radioimmunoassay}

Conditioned maturation medium was collected after 44 $\mathrm{h}$ of culture and stored at $-20^{\circ} \mathrm{C}$. $\mathrm{PGE}_{2}$ concentration was quantified using charcoal-dextran-coated radioimmunoassay methods as described previously (Marei et al., 2009). Briefly, standards (range: $2.05-10 \mathrm{ng} / \mathrm{mL}$ ) or samples were mixed with anti-PGE ${ }_{2}$ serum (from Dr. N.L. Poyser, University of Edinburgh, Edinburgh, United Kingdom) and tritiated tracer $([5,6,8,11,12,14,15$ (n)-3H]-PGE Amersham International, Amersham, United Kingdom) in duplicate. After overnight incubation at $4^{\circ} \mathrm{C}$, dextrancoated charcoal suspension containing $0.4 \%$ dextran ( $\mathrm{T}-$ 70; Amersham Pharmacia Biotech, Uppsala, Sweden) and $2 \%$ neutralized charcoal was added to all tubes, except the that used for the total count. Tubes were incubated at $4^{\circ} \mathrm{C}$ for $10 \mathrm{~min}$, followed by centrifugation at $2000 \times \mathrm{g}$ for 10 min. The supernatant was removed into $6-\mathrm{mL}$ scintillation vials containing $4 \mathrm{~mL}$ scintillation fluid (Ultima Gold; Packard Bioscience BV, Pangbourne, United Kingdom) and counted for $2 \mathrm{~min}$. $\mathrm{PGE}_{2}$ concentration was calculated using a semi-logarithmic plot at a limit of detection of 2 $\mathrm{pg} /$ tube. The intra-assay coefficient of variation was $3.5 \%$, whereas the inter-assay coefficient was $6.3 \%$.

\section{Measurement of E2 and P4 by enzyme-linked immunosorbent assay (ELISA)}

The steroidogenic activity of cumulus cells was assessed in the maturation medium according to the procedure previously described by Maya-Soriano et al. (2013) Briefly, E2 and P4 concentrations were determined after $44 \mathrm{~h}$ of IVM using commercial enzyme immunoassay kits (estradiol ELISA kit 402110 and progesterone (ultra) ELISA kit 402310, respectively; Neogen Corporation, Lexington, KY, USA) according to manufacturer instructions. The assay was validated by determination of assay specificity (dilutional parallelism), accuracy from spike recovery (101.1\% and $89.6 \%$ for E2 and P4 assays, respectively), precision from intra-assay variability $(3.8 \%$ and $3.2 \%$ for E2 and P4 assays, respectively), and sensitivity (0.03 and $0.2 \mathrm{ng} / \mathrm{mL}$ for E2 and P4 assays, respectively).

\section{Assessment of embryo quality}

Apoptotic cells in blastocyst embryos were detected using an in situ cell death detection kit (Roche Diagnostics, Mannheim, Germany). Blastocyst embryos were washed three times in DPBS with $0.1 \%$ polyvinylpyrrolidone and fixed in $4 \%(\mathrm{v} / \mathrm{v})$ paraformaldehyde diluted in DPBS for 1 $h$ at between $\sim 24^{\circ} \mathrm{C}$ and $\sim 28^{\circ} \mathrm{C}$. For membrane permeabilization, fixed embryos were incubated in DPBS containing $0.1 \%(\mathrm{v} / \mathrm{v})$ Triton $\mathrm{X}-100$ for $30 \mathrm{~min}$ at $4^{\circ} \mathrm{C}$. Fixed embryos were incubated in terminal deoxynucleotidyl transferase-mediated dUDP nick-end labeling (TUNEL) reaction medium for $1 \mathrm{~h}$ at $38.5^{\circ} \mathrm{C}$ in the dark, washed, transferred into $2 \mathrm{mg} / \mathrm{mL} 4^{\prime}, 6$-diamidino-2-phenylindole (DAPI), and mounted onto slides. Whole-mount embryos were examined using an epifluorescence microscope (Olympus, Tokyo, Japan) to assess the TUNEL assay and DAPI staining. The number of apoptotic nuclei and the total number of nuclei were counted.

\section{Statistical analysis}

Binominal data from oocyte nuclear maturation, cleavage rate, and developmental rate of blastocyst embryos were converted into percentages. These data were then analyzed using the Student's $t$ test. Data for the cumulus expansion, total and apoptotic cell numbers, $\mathrm{PGE}_{2}$ 

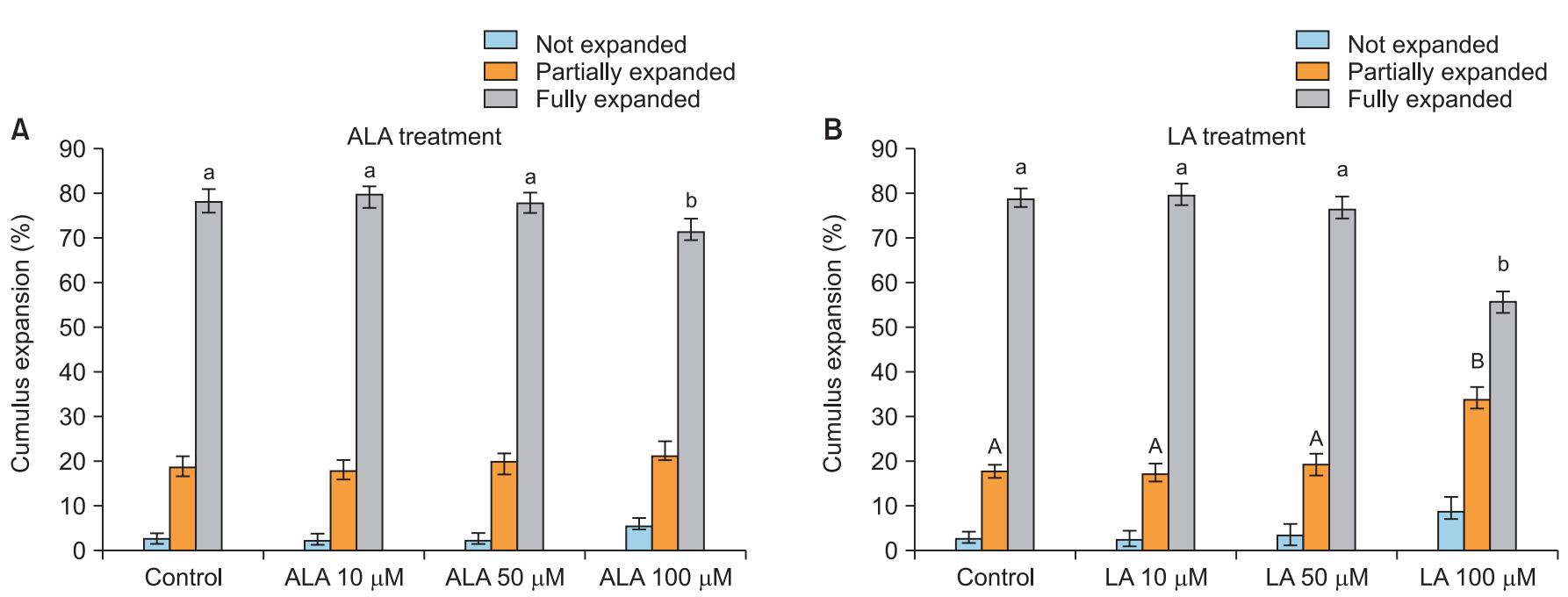

Fig. 1. Effect of ALA and LA concentrations on cumulus-cell expansion during IVM of porcine follicular oocytes. Cumulus-cell expansion of COCs treated in the presence or absence of (A) ALA or (B) LA for $44 \mathrm{~h}$. Results are presented as the mean \pm SEM of seven replicates. Different superscript letters indicate significant differences between experimental groups $(p<0.05)$. ALA; a-linolenic acid, COC; cumulus-oocyte complex, IVM; in vitro maturation, LA; linoleic acid, SEM; standard error of the mean.

Table 1. Effect of ALA concentrations during IVM on nuclear maturation of porcine follicular oocytes in vitro

\begin{tabular}{ccc}
\hline Concentration of ALA & No. of oocytes & $\begin{array}{c}\text { No. (\%) of developed } \\
\text { to Mll stage oocytes }\end{array}$ \\
\hline Control & 360 & $282(78.3)^{\mathrm{a}}$ \\
$10 \mu \mathrm{M}$ & 382 & $304(79.6)^{\mathrm{a}}$ \\
$50 \mu \mathrm{M}$ & 374 & $291(77.8)^{\mathrm{a}}$ \\
$100 \mu \mathrm{M}$ & 370 & $254(68.7)^{\mathrm{b}}$ \\
\hline
\end{tabular}

$\overline{a, b}$ Values with different superscripts are significantly different $(p<0.05)$. ALA; a-linolenic acid, IVM; in vitro maturation.

amount, and E2/P4-synthesis ratio were analyzed using a general linear model analysis of variance and reported as the mean \pm standard error of the mean (SEM). A $p<0.05$ was considered statistically significant.

\section{RESULTS}

\section{Cumulus expansion and oocyte nuclear maturation}

The effect of ALA or LA supplementation to IVM medium on cumulus expansion, and oocyte nuclear maturation is shown in Fig. 1, Tables 1 and 2. The highest concentration $(100 \mu \mathrm{M})$ of ALA and LA significantly decreased the expansion rate of fully expanded cumulus cells at $44 \mathrm{~h}$ after IVM as compared with each of the other groups, with the reduction in rate slightly higher in the LA-treatment group ( $p<0.05$; Fig. 1$)$. The results from oocyte maturation did not show differences in the percentage of oocytes
Table 2. Effect of LA concentrations during IVM on nuclear maturation of porcine follicular oocytes in vitro

\begin{tabular}{ccc}
\hline Concentration of LA & No. of oocytes & $\begin{array}{c}\text { No. (\%) of developed } \\
\text { to MIl stage oocytes }\end{array}$ \\
\hline Control & 341 & $269(79.1)^{\mathrm{a}}$ \\
$10 \mu \mathrm{M}$ & 375 & $300(80.0)^{\mathrm{a}}$ \\
$50 \mu \mathrm{M}$ & 360 & $277(77.1)^{\mathrm{a}}$ \\
$100 \mu \mathrm{M}$ & 370 & $208(56.2)^{\mathrm{b}}$ \\
\hline
\end{tabular}

$\overline{a, b}$ Values with different superscripts are significantly different $(p<0.05)$. $\mathrm{LA}$; linoleic acid, IVM; in vitro maturation.

at the MII stage at $44 \mathrm{~h}$ of IVM between the $0 \mu \mathrm{M}, 10 \mu \mathrm{M}$, and $50 \mu \mathrm{M} \mathrm{ALA}$ - and LA-treatment groups. By contrast, significantly lower rates of MII-stage oocytes were observed in the $100 \mu \mathrm{M}$ ALA- and LA-treatment groups as compared with the other groups ( $p<0.05$; Tables 1 and 2).

\section{$\mathrm{PGE}_{2}$ synthesis}

Fig. 2 shows the $\mathrm{PGE}_{2}$ concentration in the spent medium after IVM of 100 porcine follicular oocytes for $44 \mathrm{~h}$ treated with $0 \mu \mathrm{M}, 10 \mu \mathrm{M}, 50 \mu \mathrm{M}$, or $100 \mu \mathrm{M}$ ALA or LA. The $10 \mu \mathrm{M}, 50 \mu \mathrm{M}$, and $100 \mu \mathrm{M}$ ALA-treatment groups showed significantly decreased $\mathrm{PGE}_{2}$ concentrations as compared with the control group and in a dose-dependent manner $(p<0.05)$, whereas the $10 \mu \mathrm{M}$ and $50 \mu \mathrm{M}$ LA-treatment groups showed significantly increased $\mathrm{PGE}_{2}$ concentrations as compared with the control group and in a dose-dependent manner $(p<0.05)$. However, the 100 

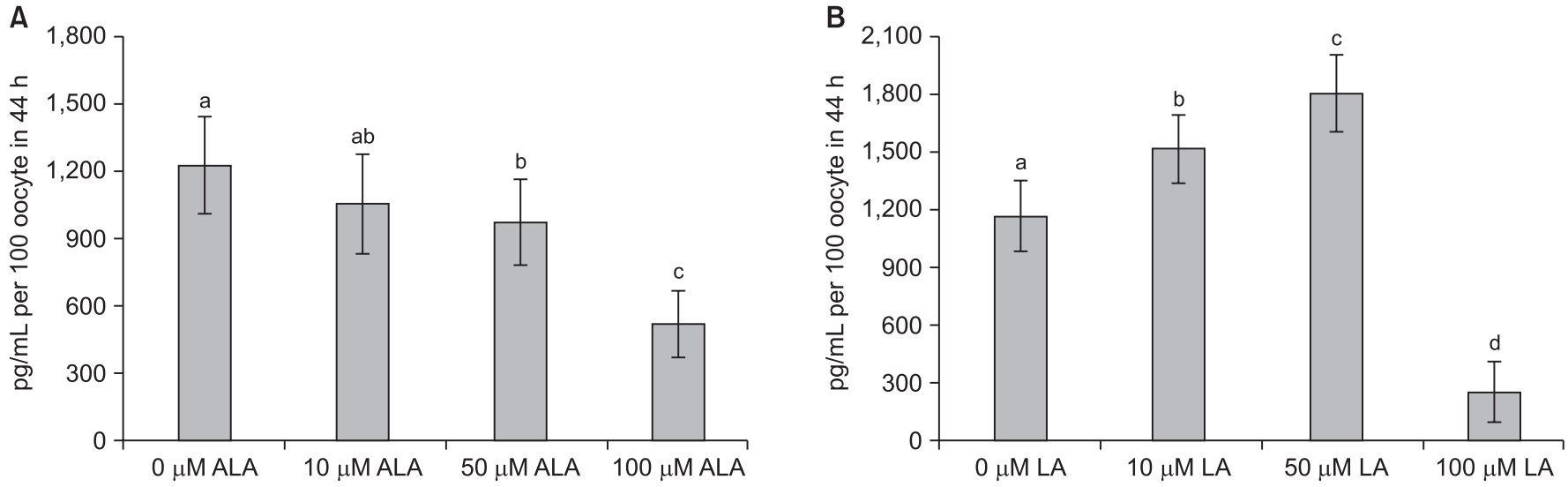

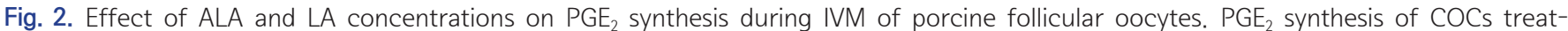
ed in the presence or absence of (A) ALA or (B) LA for $44 \mathrm{~h}$. Results are presented as the mean \pm SEM of seven replicates. Different superscript letters indicate significant differences between experimental groups $(p<0.05)$. ALA; a-linolenic acid, IVM; in vitro maturation, LA; linoleic acid, PGE2; prostaglandin $\mathrm{E}_{2}$, SEM; standard error of the mean.

Table 3. Effect of ALA concentrations during IVM on embryonic development of porcine follicular oocytes in vitro

\begin{tabular}{cccc}
\hline $\begin{array}{c}\text { Concentration } \\
\text { of ALA }\end{array}$ & $\begin{array}{c}\text { No. of } \\
\text { oocytes }\end{array}$ & $\begin{array}{c}\text { No. (\%) of } \\
\text { cleaved } \\
\text { oocytes }\end{array}$ & $\begin{array}{c}\text { No. (\%) of blastocyst } \\
\text { embryos developed } \\
\text { from cleaved oocytes }\end{array}$ \\
\hline Control & 968 & $808(83.5)^{\mathrm{a}}$ & $256(31.7)^{\mathrm{a}}$ \\
$10 \mu \mathrm{M}$ & 1,000 & $848(84.8)^{\mathrm{a}}$ & $279(32.9)^{\mathrm{a}}$ \\
$50 \mu \mathrm{M}$ & 968 & $816(84.3)^{\mathrm{a}}$ & $264(32.4)^{\mathrm{a}}$ \\
$100 \mu \mathrm{M}$ & 984 & $784(79.7)^{\mathrm{b}}$ & $230(29.3)^{\mathrm{b}}$ \\
\hline
\end{tabular}

$\overline{\text { a.b }}$ Values with different superscripts are significantly different $(p<0.05)$.

ALA; a-linolenic acid, IVM; in vitro maturation.

$\mu \mathrm{M}$ LA-treatment groups showed significantly decreased $\mathrm{PGE}_{2}$ concentrations as compared with the control group $(p<0.05)$.

\section{Cleavage and embryo development}

The effect of ALA and LA concentrations during IVM on embryonic development of porcine follicular oocytes in vitro is shown in Tables 3 and 4. The percentage of oocytes that cleaved into 4-cell stage embryos at $48 \mathrm{~h}$ after fertilization and the percentage of cleaved oocytes that developed to the blastocyst stage at day 6 after fertilization were recorded. No differences were found in the cleavage rate or blastulation rate between the control and $10 \mu \mathrm{M}$ and $50 \mu \mathrm{M}$ ALA- and LA-treatment groups, however, the $100 \mu \mathrm{M} \mathrm{ALA}-$ and LA-treatment group showed significantly lower cleavage and blastulation rates as compared with the other groups ( $p<0.05$; Table 3 and 4$)$.
Table 4. Effect of LA concentrations during IVM on embryonic development of porcine follicular oocytes in vitro

\begin{tabular}{cccc}
\hline $\begin{array}{c}\text { Concentration } \\
\text { of LA }\end{array}$ & $\begin{array}{c}\text { No. of } \\
\text { oocytes }\end{array}$ & $\begin{array}{c}\text { No. (\%) of } \\
\text { cleaved } \\
\text { oocytes }\end{array}$ & $\begin{array}{c}\text { No. (\%) of blastocyst } \\
\text { embryos developed } \\
\text { from cleaved oocytes }\end{array}$ \\
\hline Control & 741 & $606(81.7)^{\mathrm{a}}$ & $182(30.0)^{\mathrm{a}}$ \\
$10 \mu \mathrm{M}$ & 705 & $559(79.3)^{\mathrm{a}}$ & $171(30.6)^{\mathrm{a}}$ \\
$50 \mu \mathrm{M}$ & 729 & $571(78.3)^{\mathrm{a}}$ & $160(28.0)^{\mathrm{a}}$ \\
$100 \mu \mathrm{M}$ & 690 & $451(65.4)^{\mathrm{b}}$ & $67(14.9)^{\mathrm{b}}$
\end{tabular}

$\overline{a, b}$ Values with different superscripts are significantly different $(p<0.05)$. LA; linoleic acid, IVM; in vitro maturation.

\section{Embryo quality}

The effect of ALA and LA concentrations during IVM on the quality of in vitro-produced porcine blastocyst embryos assessed by the number of total and apoptotic cells is shown in Tables 5 and 6 . The number of total and apoptotic cells from in vitro-produced porcine blastocyst embryos at 6 days after fertilization was recorded. Both the $50 \mu \mathrm{M}$ ALA- and $10 \mu \mathrm{M}$ LA-treatment groups showed significantly higher numbers of total cells and lower numbers of apoptotic cells as compared with the other groups $(p<0.05$; Tables 5 and 6). Apoptosis was measured using the TUNEL assay, which allows for the identification of fragmented DNA. As shown in Fig. 3, apoptotic nuclei appeared green.

\section{E2/P4-synthesis ratio}

Fig. 4 shows the E2/P4-synthesis ratio in the spent medium after IVM from 100 porcine follicular oocytes in 
the presence of $0 \mu \mathrm{M}, 10 \mu \mathrm{M}, 50 \mu \mathrm{M}$, or $100 \mu \mathrm{M}$ ALA and LA. Both the $50 \mu \mathrm{M}$ and $100 \mu \mathrm{M}$ ALA-treatment groups showed significantly higher E2/P4-synthesis ratios as compared with the control group and in a dose-dependent manner ( $p<0.05$; Fig. 4). Moreover, the $10 \mu \mathrm{M} \mathrm{LA}-$ treatment group showed a significantly higher E2/P4synthesis ratio as compared with the other groups ( $p<$ 0.05), whereas the $100 \mu \mathrm{M}$ LA-treatment group showed a significantly lower E2/P4-synthesis ratio was compared with the other groups $(p<0.05)$.

\section{DISCUSSION}

To explain the effect of ALA and LA on nuclear, cytoplasmic, and physiological changes occurring during oocyte maturation, we measured alterations in oocyte maturation rate, cumulus-cell expansion, and embryo-

Table 5. Effect of ALA concentrations during IVM on the number of total cells and apoptotic cells produced by porcine blastocyst embryos in vitro

\begin{tabular}{cccc}
\hline $\begin{array}{c}\text { Concentration } \\
\text { of ALA }\end{array}$ & $\begin{array}{c}\text { No. of } \\
\text { examined } \\
\text { blastocyst } \\
\text { embryos }\end{array}$ & $\begin{array}{c}\text { No. of total } \\
\text { cells in } \\
\text { blastocyst } \\
\text { embryos }\end{array}$ & $\begin{array}{c}\text { No. of apoptotic } \\
\text { cells in } \\
\text { blastocyst } \\
\text { embryos }\end{array}$ \\
\hline Control & 25 & $41.8 \pm 3.1^{\mathrm{a}}$ & $1.5 \pm 0.9^{\mathrm{a}}$ \\
$10 \mu \mathrm{M}$ & 28 & $41.4 \pm 2.9^{\mathrm{a}}$ & $1.3 \pm 1.1^{\mathrm{a}}$ \\
$50 \mu \mathrm{M}$ & 29 & $47.4 \pm 2.7^{\mathrm{b}}$ & $0.9 \pm 0.8^{\mathrm{b}}$ \\
$100 \mu \mathrm{M}$ & 23 & $40.1 \pm 3.2^{\mathrm{a}}$ & $1.5 \pm 1.2^{\mathrm{a}}$ \\
\hline
\end{tabular}

Results are presented as the mean \pm SEM from six replicates. Different superscript letters indicate significant differences between experimental groups $(p<0.05)$.

ALA; a-linolenic acid, IVM; in vitro maturation, SEM; standard error of the mean. developmental potential after fertilization. Additionally, we investigated changes in $\mathrm{PGE}_{2}$ and sex-steroid (E2 and P4) synthesis in the spent media.

Our study found that supplementation with $10 \mu \mathrm{M}$ and $50 \mu \mathrm{M}$ ALA did not affect oocyte nuclear maturation or cumulus expansion, whereas $100 \mu \mathrm{M}$ ALA supplementation resulted in a significant inhibitory effect (Table 1 and Fig. 1A). These results implied that the highest experimental dose of ALA supplementation inhibited IVM of porcine COCs. A similar effect was observed for $200 \mu \mathrm{M}$ ALA supplementation in the IVM medium of prepubertal sheep oocytes, where there was a negative effect on nuclear maturation and cumulus cell expansion (Ghaffarilaleh et al., 2014). In a bovine study conducted by Marei et al. (2009), COC treatment with $50 \mu$ M ALA significantly increased oocyte percentages at the MII stage as compared with that observed in the untreated control group. However, high doses $(100 \mu \mathrm{M}$ and $200 \mu \mathrm{M})$ of ALA treatment

Table 6. Effect of LA concentrations during IVM on the number of total cells and apoptotic cells produced by porcine blastocyst embryos in vitro

\begin{tabular}{cccc}
\hline $\begin{array}{c}\text { Concentration } \\
\text { of LA }\end{array}$ & $\begin{array}{c}\text { No. of } \\
\text { examined } \\
\text { blastocyst } \\
\text { embryos }\end{array}$ & $\begin{array}{c}\text { No. (mean) of } \\
\text { total cells in } \\
\text { blastocyst } \\
\text { embryos }\end{array}$ & $\begin{array}{c}\text { No. (mean) of } \\
\text { apoptotic cells } \\
\text { in blastocyst } \\
\text { embryos }\end{array}$ \\
\hline Control & 25 & $40.8 \pm 3.2^{\mathrm{a}}$ & $1.5 \pm 0.8^{\mathrm{a}}$ \\
$10 \mu \mathrm{M}$ & 25 & $45.6 \pm 3.4^{\mathrm{b}}$ & $1.2 \pm 1.1^{\mathrm{b}}$ \\
$50 \mu \mathrm{M}$ & 25 & $41.4 \pm 2.2^{\mathrm{a}}$ & $1.5 \pm 0.9^{\mathrm{a}}$ \\
$100 \mu \mathrm{M}$ & 25 & $38.1 \pm 3.9^{\mathrm{a}}$ & $1.6 \pm 1.1^{\mathrm{a}}$ \\
\hline
\end{tabular}

Results are presented as the mean \pm SEM from five replicates. Different superscript letters indicate significant differences between experimental groups $(p<0.05)$.

LA; linoleic acid, IVM; in vitro maturation, SEM; standard error of the mean.
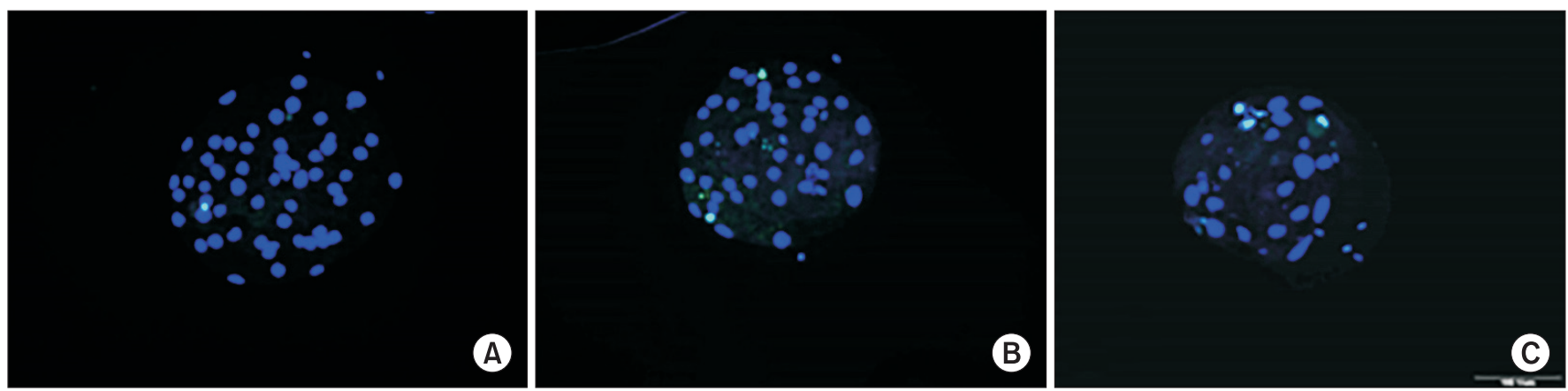

Fig. 3. Epifluorescent images of blastocyst embryos produced in vitro undergoing apoptosis. (A) Good quality, (B) normal quality, (C) bad quality. Chromatin content was assessed by DAPI staining (blue). TUNEL staining assessing DNA fragmentation (green). Scale bar = $100 \mu \mathrm{m}$. DAPI, 4',6-diamidino-2-phenylindole; TUNEL, terminal deoxynucleotidyl transferase-mediated dUDP nick-end labeling. 
A

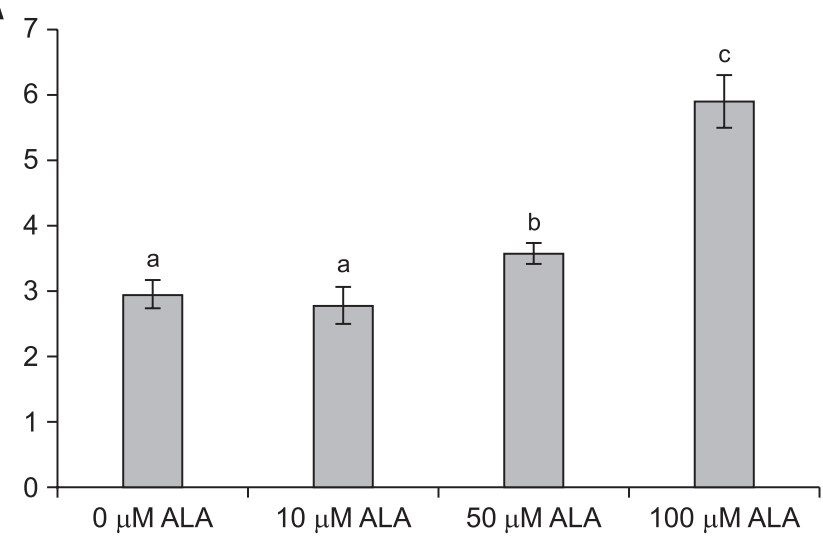

B

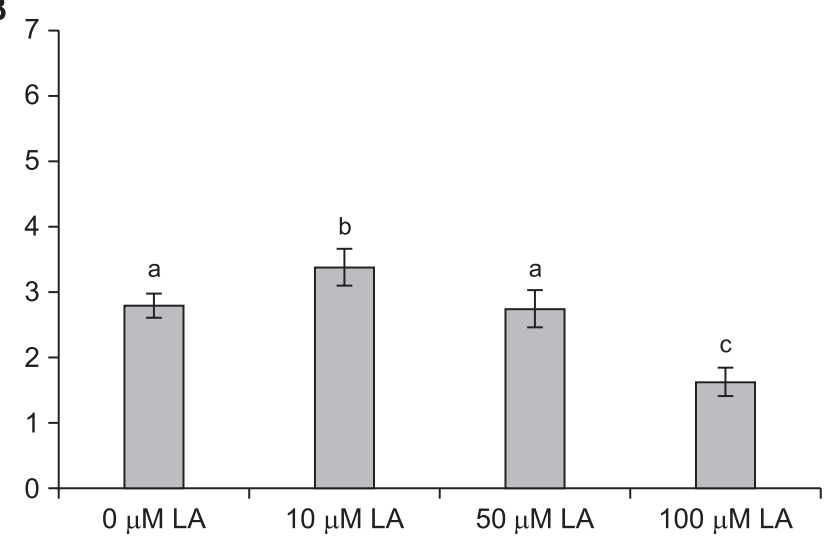

Fig. 4. Effect of ALA and LA concentrations on E2/P4-synthesis ratio during IVM of porcine follicular oocytes. E2/P4-synthesis ratio of COCs treated in the presence or absence of (A) ALA or (B) LA for $44 \mathrm{~h}$. Results are presented as the mean \pm SEM from 20 replicates. Different superscript letters indicate significant differences between experimental groups $(p<0.05)$. ALA; a-linolenic acid, E2; estrogen, IVM; in vitro maturation, LA; linoleic acid, P4; progesterone, SEM; standard error of the mean.

reduced the number of COCs containing fully expanded cumulus cells. These results were similar to our results described here. Moreover, our results indicated that $100 \mu \mathrm{M}$ LA supplementation of maturation medium significantly inhibited (similar to ALA, but stronger) cumulus-cell expansion and oocyte nuclear maturation (Fig. 1B and Table 2). These results implied that the addition of high doses of LA also inhibited IVM of porcine COCs during IVM. Similar result was reported that LA significantly inhibits GV breakdown (35\% in LA vs. $81 \%$ in control) in cumulusfree oocytes (Homa et al., 1992). Additionally, fatty acidcontent analysis of the bovine follicular fluid collected from different-sized follicles showed significant decreases in LA concentration in large follicles as compared with small follicles. These results suggested that high LA concentrations could be a contributing factor to oocyte arrest at the GV stage. Subsequently, Marei et al. (2010) reported that LA supplementation to bovine oocytes during maturation alters the molecular mechanisms regulating oocyte maturation, resulting in a decreased percentage of oocytes at the MII stage and inhibition of cumuluscell expansion in a dose-dependent manner. These inhibitory effects of ALA and LA supplementation may be related to changes in cell membrane fluidity and $\mathrm{PGE}_{2}$ synthesis. First, PUFAs are necessary components of cell membranes; therefore, altering ALA and LA concentration can change membrane fluidity and affect processes mediated by the membrane due to the presence of unsaturated fatty acids with numerous double bonds, which cause hydrocarbon-chain bending and result in the formation of free spaces (Wiktorowska-Owczarek et al., 2015). In this context, inhibition of oocyte maturation by ALA and LA supplementation might be mediated by altering cumuluscell membrane response to gonadotropic stimulation. In addition, ALA and LA serve as precursors for the synthesis of $\mathrm{PGE}_{2}$, which plays an important role in cumulus-cell expansion and oocyte maturation (Marei et al., 2014). In mammals, LA can be transformed to DGLA and AA, and ALA can be transformed to EPA, and specifically, DGLA is a precursor for 1-series $\mathrm{PG}$ synthesis $\left(\mathrm{PGF}_{1}\right.$ or $\left.\mathrm{PGE}_{1}\right), \mathrm{AA}$ is a precursor for 2-series PG synthesis $\left(\mathrm{PGF}_{2}\right.$ or $\left.\mathrm{PGE}_{2}\right)$, and EPA is a precursor for 3-series PG synthesis $\left(\mathrm{PGF}_{3}\right.$ or $\mathrm{PGE}_{3}$ ) (Wathes et al., 2007).

In our porcine study (Fig. 2A), ALA supplementation (10 $\mu \mathrm{M}, 50 \mu \mathrm{M}$, and $100 \mu \mathrm{M})$ resulted in a dose-dependent decrease in $\mathrm{PGE}_{2}$ synthesis in the spent medium during IVM. These results suggested that porcine COCs are capable of metabolizing ALA and moderating $\mathrm{PGE}_{2}$ synthesis. A decrease in $\mathrm{PGE}_{2}$ synthesis through the addition of high ALA concentrations during IVM could be associated with inhibited cumulus expansion and the decreased number of MII-stage oocytes (Fig. 1A and Table 1). As previously reported (Lands et al., 1992), PUFAs absorbed from the cellular environment are competitively synthesized into 1-, 2-, and 3- series PGs using a limited number of metabolic enzymes (especially desaturase and cyclooxygenase). This competition theory agrees with our results showing that high-dose ALA, which is a precursor of 3-series PGs, inhibited the synthesis of $\mathrm{PGE}_{2}$, a 2-series PG. In sheep (Ghaffarilaleh et al., 2014) and bovine species (Marei et 
al., 2009), COCs treated with ALA exhibit significantly increased $\mathrm{PGE}_{2}$ concentrations as compared with the control group. In these studies, the conflicting results (when compared with our findings) might be species-specific. In our study, supplementation with $10 \mu \mathrm{M}$ and $50 \mu \mathrm{M}$ LA resulted in a marked increase in $\mathrm{PGE}_{2}$ synthesis in the spent medium, whereas supplementation with $100 \mu \mathrm{M}$ LA caused a significant decrease in $\mathrm{PGE}_{2}$ synthesis (Fig. 2B). A decrease in $\mathrm{PGE}_{2}$ synthesis following the addition of high LA concentrations during IVM could be associated with inhibited cumulus expansion and decreased numbers of MII-stage oocytes. In their bovine study, Marei et al. (2010) reported that LA supplementation $(10 \mu \mathrm{M}, 50$ $\mu \mathrm{M}$, and $100 \mu \mathrm{M})$ resulted in a dose-dependent increase in $\mathrm{PGE}_{2}$ synthesis during IVM; however, increased $\mathrm{PGE}_{2}$ synthesis could not overcome the inhibitory effect of LA on cumulus-cell expansion or oocyte maturation. The LA could be transformed to both DGLA (a precursor of 1-series PGs) and AA (a precursor of 2-series PGs) in mammals (Kinsella et al., 1990). When there is enough enzyme (desaturase and cyclooxygenase), added LA could be a precursor for both the 1- and 2-series PG, thus increased $\mathrm{PGE}_{2}$ synthesis. However, when enzymes are limited, depending on the proportions of the various precursors present, 1-series PGs might be produced at the expense of 2-series PGs (Wathes et al., 2009). Therefore, in our porcine study, decreased $\mathrm{PGE}_{2}$ synthesis following $100 \mu \mathrm{M}$ LA supplementation might be explained by these interactions and competitive effects. These results also suggested that porcine COCs are capable of metabolizing LA and producing moderate amounts of $\mathrm{PGE}_{2}$. In addition, decrease in $\mathrm{PGE}_{2}$ synthesis below an appropriate level could be associated with inhibited cumulus expansion and decreased MII-stage progression of porcine oocytes matured in $100 \mu \mathrm{M}$ LA. The above mentioned, relation to changes in cumulus-cell membrane fluidity and hormonal responsibility by addition PUFAs were also considered and needs further investigation.

Our results in porcine oocytes revealed no significant differences in cleavage or blastocyst rates between controls and $10 \mu \mathrm{M}$ and $50 \mu \mathrm{M}$ ALA-treated groups. However, oocytes matured in the presence of $100 \mu \mathrm{M}$ ALA had significantly lower percentage of cleaved embryos and blastocyst rates. In addition, oocytes matured in the presence of $50 \mu \mathrm{M}$ ALA showed higher-quality blastocyst embryos as demonstrated by higher cell number and decreased apoptosis (Tables 3 and 5; Fig. 3). In contrast to our findings, improved developmental rates to blastocyst-stage embryos were reported in bovine species (Marei et al., 2009), although significant increases in total cell number and decreased apoptosis were reported in both sheep (Ghaffarilaleh et al., 2014) and bovine species (Marei et al., 2009). In the bovine study (Marei et al., 2009), the authors suggested that these ALA-specific effects during IVM are mediated through both cyclic adenosine monophosphate and $\mathrm{PGE}_{2}$ synthesis, whereas in sheep (Ghaffarilaleh et al., 2014), the authors suggest that these effects are associated with alterations in released reproductive hormones.

Little is known about the relation between changes in synthesis of these hormones (E2 and P4) in follicular fluid and production of good quality embryo from those follicles. However, near the time of ovulation, the phenomenon of prominent shift in the concentrations of E2 and P4 during the phase of final oocyte maturation (de Loos et al., 1991) indicate that the change of E2/P4-synthesis ratios is very important during maturation process. The finding that E2/P4 ratios in follicular fluid has been used as a surrogate marker of healthy and atretic follicles (Modina et al., 2014) supports this suggestion. High doses (100 $\mu \mathrm{M})$ of ALA and LA treatment groups were excluded from the discussion, because they did not show normal maturation process such as abnormal cumulus cell expansion. In our study (Fig. 4A), the $50 \mu \mathrm{M}$ ALA-treatment group showed higher E2/P4-synthesis ratios than the control group (3.59 \pm 0.16 vs. $2.97 \pm 0.22$, respectively; $p<0.05$ ). Moreover, oocytes matured in the presence of $10 \mu \mathrm{M}$ LA resulted in better-quality blastocyst embryos in terms of higher cell number and decreased apoptosis (Table 4 and 6; Fig. 3), and this group showed a significantly higher E2/P4-synthesis ratio in spent medium relative to that observed in the control group $(3.4 \pm 0.28$ vs. $2.81 \pm 0.19$; $p<0.05)$. These results are noteworthy and suggested the ability of porcine COCs to metabolize ALA and LA and moderate E2/P4 synthesis, with the optimal balance of hormone levels associated with the production of goodquality embryos. However, it is unclear whether these actions are mediated directly through the effect of PUFAs on $\mathrm{E} 2 / \mathrm{P} 4$ synthesis or indirectly through altered $\mathrm{PGE}_{2}$ secretion, because $\mathrm{PGE}_{2}$ are thought act as luteotrophic factors in early luteal phase (Ghaffarilaleh et al., 2014) and affected E2 and P4 secretion (Wathes et al., 2007). Thus, 
further investigations are needed to determine the association between $\mathrm{PGE}_{2}$ secretion and $\mathrm{E} 2$ and $\mathrm{P} 4$ secretion.

\section{CONCLUSION}

In conclusion, the addition of optimal concentrations of ALA and LA to IVM medium for porcine oocytes resulted in physiological changes that increased in vitro production of high-quality blastocyst embryos exhibiting high cell number and decreased apoptosis. However, high doses of ALA and LA treatment results in detrimental effects. These results seem to be closely related to changes in $\mathrm{PGE}_{2}$ synthesis and E2/P4-synthesis ratio. Further studies are required to determine the optimal application of fatty acid supplementation in porcine reproduction. These results can be used for both the establishment of an in vitro culture system for oocytes and for livestock-breeding programs through the use of an adequately balanced diet or supply of pharmacologic medications, as well as for basic research.

\section{CONFLICTS OF INTEREST}

No potential conflict of interest relevant to this article was reported.

\section{ACKNOWLEDGEMENTS}

This research has been supported by University of Daegu, 2016. The author of this paper, Kang-Sig Kim, was enrolled in the department of biotechnology, Graduate School of Daegu University in 2016.

\section{ORCID}

Kang-Sig Kim: https://orcid.org/0000-0003-2363-9248

Hum-Dai Park: https://orcid.org/0000-0002-3721-9167

\section{REFERENCES}

Abayasekara DRE, Wathes DC. 1999. Effects of altering dietary fatty acid composition on PG synthesis and fertility. Prostaglandins Leukot Essent Fatty Acids. 61:275-87.

Abeydeera LR, Day BN. 1997. In vitro penetration of pig oocytes in a modified Tris-buffered medium: effect of BSA, caffeine and calcium. Theriogenology. 48:537-44.

Beker-van Woudenberg AR, van Tol HT, Roelen BA, Colenbrander B, Bevers MM. 2004. Estradiol and its membrane- impermeable conjugate (estradiol-bovine serum albumin) during in vitro maturation of bovine oocytes: effects on nuclear and cytoplasmic maturation, cytoskeleton, and embryo quality. Biol Reprod. 70:1465-74.

Carro M, Buschiazzo J, Ríos GL, Oresti GM, Alberio RH. 2013. Linoleic acid stimulates neutral lipid accumulation in lipid droplets of maturing bovine oocytes. Theriogenology. 79:687-94.

Childs S, Hennessy AA, Sreenan JM, Wathes DC, Cheng Z, Stanton C, et al. 2008. Effect of level of dietary n-3 polyunsaturated fatty acid supplementation on systemic and tissue fatty acid concentrations and on selected reproductive variables in cattle. Theriogenology. 70:595-611.

de Loos FA, Bevers MM, Dieleman SJ, Kruip TA. 1991. Follicular and oocyte maturation in cows treated for superovulation. Theriogenology. 35; 537-46.

Fouladi-Nashta AA, Gutierrez CG, Gong JG, Garnsworthy PC, Webb R. 2007. Impact of dietary fatty acids on oocyte quality and development in lactating dairy cows. Biol Reprod. 77:917 .

Ghaffarilaleh V, Fouladi-Nashta A, Paramio MT. 2014. Effect of a-linolenic acid on oocyte maturation and embryo development of prepubertal sheep oocytes. Theriogenology. 82:68696.

Gulliver CE, Friend MA, King BJ, Clayton EH. 2012. The role of omega-3 polyunsaturated fatty acids in reproduction of sheep and cattle. Anim Reprod Sci. 131:9-22.

Hizaki H, Segi E, Sugimoto Y, Hirose M, Saji T, Ushikubi F, et al. 1999. Abortive expansion of the cumulus and impaired fertility in mice lacking the prostaglandin E receptor subtype EP(2). Proc Natl Acad Sci. U S A. 96:10501-6.

Homa H, Cantley TC, Stumpf TT, Terlouw SL, Day BN. 1994. In vitro development of in vitro-matured porcine oocytes following chemical activation or in vitro fertilization. Biol Reprod. 50:1072-7.

Homa ST, Brown CA. 1992. Changes in linoleic acid during follicular development and inhibition of spontaneous breakdown of germinal vesicles in cumulus-free bovine oocytes. J Reprod Fertil. 94:153-60.

Hyttel P, Callesen H, Greve T. 1986. Ultrastructural features of preovulatory oocyte maturation in superovulated cattle. J Reprod Fertil. 76:645-56.

Kinsella JE, Lokesh B, Broughton S, Whelan J. 1990. Dietary polyunsaturated fatty acids and eicosanoids: potential effects on the modulation of inflammatory and immune cells: an overview. Nutrition. 6:24-44; discussion 59-62.

Lands WE. 1992. Biochemistry and physiology of n-3 fatty acids. FASEB J. 6:2530-6.

Lubahn DB, Moyer JS, Golding TS, Couse JF, Korach KS, Smithies O. 1993. Alteration of reproductive function but not prenatal sexual development after insertional disruption of the mouse estrogen receptor gene. Proc Natl Acad Sci U S A. 90:11162-6.

Lydon JP, DeMayo FJ, Funk CR, Mani SK, Hughes AR, Montgomery Jr CA, et al. 1995. Mice lacking progesterone recep- 
tor exhibit pleiotropic reproductive abnormalities. Genes Dev. 9:2266-78.

Marei WF, Abayasekara DRE, Wathes DC, Fouladi-Nashta AA. 2014. Role of PTGS2-generated PGE2 during gonadotrophin-induced bovine oocyte maturation and cumulus cell expansion. Reprod Biomed Online. 28:388-400.

Marei WF, Wathes DC, Fouladi-Nashta AA. 2009. The effect of linolenic acid on bovine oocyte maturation and development. Biol Reprod. 81:1064-72.

Marei WF, Wathes DC, Fouladi-Nashta AA. 2010. Impact of linoleic acid on bovine oocyte maturation and embryo development. Reproduction. 139:979-88.

Marei WF, Wathes DC, Fouladi-Nashta AA. 2012. Differential effects of linoleic and alpha-linolenic fatty acids on spatial and temporal mitochondrial distribution and activity in bovine oocytes. Reprod Fertil Dev. 24:679-90.

Mattos R, Staples C, Thatcher W. 2000. Effects of dietary fatty acids on reproduction in ruminants. Rev Reprod. 5:38-45.

Maya-Soriano MJ, López-Gatius F, Andreu-Vázquez C, LópezBéjar M. 2013. Bovine oocytes show a higher tolerance to heat shock in the warm compared with the cold season of the year. Theriogenology. 79:299-305.

Modina SC, Tessaro I, Lodde V, Franciosi F, Corbani D, Luciano AM. 2014. Reductions in the number of mid-sized antral follicles are associated with markers of premature ovarian senescence in dairy cows. Reprod Fertil Dev. 26:235-44.

Neal P, Baker TG, McNatty KP, Scaramuzzi RJ. 1975. Influence of prostaglandins and human chorionic gonadotrophin on progesterone concentration and oocyte maturation in mouse ovarian follicles maintained in organ culture. J Endocrinol. 65:19-25.

Nuttinck F, Gall L, Ruffini S, Laffont L, Clement L, Reinaud P, et al. 2011. PTGS2-related PGE2 affects oocyte MAPK phosphorylation and meiosis progression in cattle: late effects on early embryonic development. Biol Reprod. 84:1248-57.

Petters RM, Wells KD. 1993. Culture of pig embryos. [Review]. J Reprod Fertil Suppl. 48:61-73.

Santos JE, Bilby TR, Thatcher WW, Staples CR, Silvestre FT.
2008. Long chain fatty acids of diet as factors influencing reproduction in cattle. Reprod Domest Anim. 43:23-30.

Segi E, Haraguchi K, Sugimoto Y, Tsuji M, Tsunekawa H, Tamba S,et al. 2003. Expression of messenger RNA for prostaglandin E receptor subtypes EP4/EP2 and cyclooxygenase isozymes in mouse periovulatory follicles and oviducts during superovulation. Biol Reprod. 68:804-11.

Siqueira LC, Barreta MH, Gasperin B, Bohrer R, Santos JT, Buratini Jr J, et al. 2012. Angiotensin II, progesterone, and prostaglandins are sequential steps in the pathway to bovine oocyte nuclear maturation. Theriogenology. 77:1779-87.

Sirard MA, Richard F, Blondin P, Robert C. 2006. Contribution of the oocyte to embryo quality. Theriogenology. 65:126-36.

Takahashi T, Morrow JD, Wang H, Dey SK. 2006. Cyclooxygenase-2-derived prostaglandin $\mathrm{E}(2)$ directs oocyte maturation by differentially influencing multiple signaling pathways. J Biol Chem. 281:37117-29.

Veshkini A, Asadi H, Khadem AA, Mohammadi-Sangcheshmeh A, Khazabi S, Aminafshar M, et al. 2015. Effect of Linolenic acid during in vitro maturation of ovine oocytes: embryonic developmental potential and mRNA abundances of genes involved in apoptosis. J Assist Reprod Genet. 32:653-9

Walsh SW, Mehta JP, McGettigan PA, Browne JA, Forde N, Alibrahim RM, et al. 2012. Effect of the metabolic environment at key stages of follicle development in cattle: focus on steroid biosynthesis. Physiol Genomics. 44:504-17.

Wathes DC, Abayasekara DR, Aitken RJ. 2007. Polyunsaturated fatty acids in male and female reproduction. Biol Reprod. 77:190-201.

Wiktorowska-Owczarek A, Berezinska M, Nowak JZ. 2015. PUFAs: structures, metabolism, and functions. Adv Clin Exp Med. 24:931-41.

Yamashita Y, Shimada M, Okazaki T, Maeda T, Terada T. 2003. Production of progesterone from de novo-synthesized cholesterol in cumulus cells and its physiological role during meiotic resumption of porcine oocytes. Biol Reprod. 68; 1193-98. 